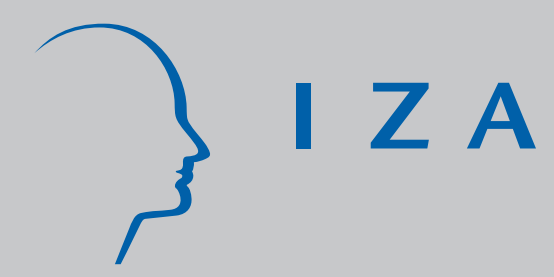

IZA DP No. 1076

Employment Effects of Early Interventions on J ob Search Programs

Andrea Weber

Helmut Hofer

March 2004 


\title{
Employment Effects of Early Interventions on Job Search Programs
}

\author{
Andrea Weber \\ Institute for Advanced Studies, Vienna \\ and IZA Bonn \\ Helmut Hofer \\ Institute for Advanced Studies, Vienna
}

Discussion Paper No. 1076

March 2004

\author{
IZA \\ P.O. Box 7240 \\ 53072 Bonn \\ Germany
}

Phone: +49-228-3894-0

Fax: +49-228-3894-180

Email: iza@iza.org

Any opinions expressed here are those of the author(s) and not those of the institute. Research disseminated by IZA may include views on policy, but the institute itself takes no institutional policy positions.

The Institute for the Study of Labor (IZA) in Bonn is a local and virtual international research center and a place of communication between science, politics and business. IZA is an independent nonprofit company supported by Deutsche Post World Net. The center is associated with the University of Bonn and offers a stimulating research environment through its research networks, research support, and visitors and doctoral programs. IZA engages in (i) original and internationally competitive research in all fields of labor economics, (ii) development of policy concepts, and (iii) dissemination of research results and concepts to the interested public.

IZA Discussion Papers often represent preliminary work and are circulated to encourage discussion. Citation of such a paper should account for its provisional character. A revised version may be available on the IZA website (www.iza.org) or directly from the author. 
IZA Discussion Paper No. 1076

March 2004

\section{ABSTRACT \\ Employment Effects of Early Interventions on Job Search Programs*}

We investigate the dependence of the program effect on varying entry times for a low cost job-search assistance program in Austria. The Austrian targeting policy is to admit every unemployed to a job-search program before the fourth month. The program effect is measured by a shift in the transition rate into employment upon program entry, using the timing-of-events method. Our findings are that the program effect is positive and does not vary significantly for program entries during the first year of unemployment, but it drops drastically thereafter.

JEL Classification: $\quad$ C14, C41, J64

Keywords: active labour market policy, early intervention, treatment effect, multivariate duration model

Corresponding author:

Andrea Weber

Department of Economics and Finance

Institute for Advanced Studies

Stumpergasse 56

1060 Vienna

Austria

Tel.: +43159991147

Fax: +43159991163

Email: andrea.weber@ihs.ac.at

\footnotetext{
* The authors thank Marius Wilk for essential support in providing the data, and Tsvetan Bikov for help with data processing. Financial support for this research was granted from the Jubiläumsfonds of the Austrian National Bank grant No. 9242.
} 


\section{Introduction}

Active labour market policy (ALMP) is regarded as an important tool to foster employment growth and to reduce unemployment. Most active measures aim to reintegrate the long term unemployed into the labour market. There is, however, growing interest in preventive approaches, with the intervention taking place before the individual becomes long term unemployed. Policy guidelines by the OECD and the European Commission recommend the concept of early intervention according to which treatment should start early (European Commission, 1998; OECD, 1998). The main objectives to early intervention are increasing costs, as the target group of participants becomes wider, and the risk of deadweight losses (individuals participating in training who would have found a job anyway). However, there is little empirical evidence on this debate (OECD, 1994). Especially the question how the program effect varies with the timing of program entry has not been addressed.

Following the recommendations of the European Employment Strategy, Austria's employment policy promoted a new type of active employment programs complementary to training programs, which had been the traditional tool of ALMP. The concept of the new program, named "job-coaching", concentrates on the activation of the unemployed and is based on early intervention (Schernhammer and Adam, 2002). Job-coaching is implemented as a part-time program, leaving time for search activities next to course participation, and it concentrates on the training of job-search related skills. In addition, jobcoaching should be available for every unemployed during the first four months of unemployment. Given the short program duration of six weeks, the costs of this program are low in comparison to traditional training and hence it can be made available for a wider target group. Expected effects of the program are an increase in search effort and motivation resulting in higher transitions to employment and a reduced risk of transitions to long term unemployment. Weber and Hofer (2003) find in a first evaluation that these aims were reached quite successfully.

In this paper we focus on the importance of the early intervention eligibility criterion. Although the target group of job-coaching participants are individuals with less than four months of unemployment duration, in the actual implementation also many longer term unemployed are admitted. This was particularly the case during the launch of job-coaching on a large scale in 1999 and 2000. This circumstance enables us to investigate whether the program effects are highest for the target group or whether also longer term unemployed benefit 
from the program.

We evaluate the program effect of job-coaching on transitions into employment using the timing-of-events method. This relatively new method, introduced by Abbring and van den Berg (2003), models the process of exit from unemployment into employment and the process of program entry simultaneously in a multivariate hazard model. The method is well suited to study time-variation in program effects (Bolvig et al., 2003). A further motivation for using the method is given by the structure of our data. We study a sample of individual unemployment spells from the inflow into unemployment. The data come from administrative records, which give accurate daily information on the employment and program participation status.

\section{The data and the evaluation strategy}

We use data on individual labour market careers from administrative sources in Austria: a $20 \%$ sample from the total inflow into unemployment from March to August 1999. ${ }^{1}$ The data contain daily information on the labour market status (employed, unemployed, out of labour force) as well as any ALMP program participation. For the empirical analysis we select the first unemployment spell during the inflow period for each individual. ${ }^{2}$ Out of the ALMP spells we select the first program spell during the unemployment spell as the one which is evaluated and we mark individuals with an ALMP spell as program participants. The set includes 32,000 individuals. In the sample a share of $19 \%$ are observed to participate in an ALMP program. Out of those $30 \%$ (1820 individuals) can be identified as job-coaching participants. Although it was planned to send every new entrant into unemployment to a job-coaching course before the fourth month of the spell had elapsed, the short time between instalment and begin of this large scale program led to a number of administrative difficulties. In the sample only $63 \%$ of the participants in job-coaching meet the target of being admitted to the program after less than 4 months of unemployment. A share $22 \%$ have been unemployed between 4 and 12 months before entering the program and $5 \%$ of the participants are long term unemployed with durations above one year.

\footnotetext{
${ }^{1}$ For a detailed description of the data set see Weber and Hofer (2003).

${ }^{2}$ If the unemployment spell ended in a transition to a job the spell is considered to be completed. If the unemployment spell ended in the transition to another state (e.g. maternity leave, out of labour force) it is considered to be censored. In our sample we observe a share of $33 \%$ censored unemployment spells.
} 
The evaluation strategy, based on the timing-of-events method, assumes that the transition rate from unemployment into employment shifts to a different level at program entry and stays constant thereafter. The program effect is, accordingly, defined by the size of this shift. Here, we especially investigate whether the program effect changes with the time of program entry. The argument for early intervention states that program entry at an early time of unemployment should correspond to a higher positive shift, whereas late program entry leads to a smaller shift. We model two simultaneous processes starting with the beginning of unemployment, namely the exit from unemployment into employment and the entry into a program, by a multivariate mixed proportional hazard (MPH) model. Let $t$ denote the time elapsed since the start of unemployment and $t_{p}$ the time until program entry. The hazard rates into employment $\theta_{u}$ and into a program $\theta_{p}$ are assumed to be of the form

$$
\begin{aligned}
\theta_{u}\left(t \mid x, t_{p}, v_{u}\right) & =\lambda_{u}(t) \exp \left(x^{\prime} \beta_{u}+\delta\left(t_{p}\right) I\left(t>t_{p}\right)+v_{u}\right) \\
\theta_{p}\left(t \mid x, v_{p}\right) & =\lambda_{p}(t) \exp \left(x^{\prime} \beta_{p}+v_{p}\right)
\end{aligned}
$$

where $\lambda_{u}(t), \lambda_{p}(t)$ represent the individual duration dependence of the hazards. $x$ denotes a set of non-time varying observable characteristics, like gender, age, education level, and labour market career variables. The effects of the observables are given by $\beta_{u}$ and $\beta_{p}$. Program entry at $t_{p}$ is expressed by the indicator $I\left(t>t_{p}\right)$ which takes the value one for program participants; $\delta\left(t_{p}\right)$ measures the program effect in dependence of the entry time. Both hazard rates also depend on unobserved variables $v_{u}$ and $v_{p}$. These unobservables may be correlated which allows for unobserved selection into the program.

The identification of the program effect relies on the fact that the values of the unobserved characteristics are constant throughout time, whereas the program effect starts only after program entry. So, by the variation in entry times it is possible to identify the program effect from the effect of unobserved heterogeneity on the hazard rate into employment. The crucial assumptions underlying the identification result are variation in observed program entry times, no advance notice of program entry, and the MPH form of the hazard rates (Abbring and van den Berg, 2003).

In our model we specify piecewise constant baseline hazards. The distribution of the unobserved variables $\left(v_{u}, v_{p}\right)$ is assumed to take on a multivariate discrete distribution, with two points of support for each variable. The variation of the program effect with entry time is modelled to have a quadratic from or alternatively by a piecewise constant function. We control for substitution 
effects arising from participation in programs other than job-coaching by modelling transitions into these programs as well. As the hazard rates provide a full characterisation of the duration distributions (Lancaster, 1990; van den Berg, 2001), we can derive the likelihood function and estimate the parameters by Maximum Likelihood.

\section{Program effects depending on entry time}

We model the dependence of the program effect on entry time by two different specifications. In the first model we assume a quadratic functional form, given by $\delta_{t_{p}}=c+\delta_{1} t_{p}+\delta_{2} t_{p}^{2}$. In the second model we use a piecewise constant functional form $\delta_{t_{p}}=\sum_{k=1}^{7} \delta_{k} I_{k}$, with the $I_{k}$ 's being dummy variables equal to one if program entry occurs between 0 to 2 months, 2 to 4 months, etc. The estimation results are given in Table $1 .^{3}$ We report the program effect in terms of the parameter $\delta$ in equation (2). A positive delta increases the hazard, thus reduces unemployment duration, and can be interpreted as a positive program effect.

Table 1: Program effects dependent of entry into the program

\begin{tabular}{|c|c|c|c|c|c|}
\hline \multicolumn{2}{|c|}{ quadratic model } & & \multicolumn{3}{|c|}{ piecewise constant model } \\
\hline & Parameter & Std.err & & Parameter & Std.err \\
\hline constant & 0.310 & $(0.052)$ & $I_{0-2}$ & 0.402 & $(0.042)$ \\
\hline$t_{p}$ & 0.460 & $(0.222)$ & $I_{2-4}$ & 0.349 & $(0.039)$ \\
\hline$t_{p}^{2}$ & -0.549 & $(0.170)$ & $I_{4-6}$ & 0.302 & $(0.063)$ \\
\hline & & & $I_{6-8}$ & 0.456 & $(0.086)$ \\
\hline & & & $I_{8-10}$ & 0.449 & $(0.112)$ \\
\hline & & & $I_{10-12}$ & 0.534 & $(0.117)$ \\
\hline & & & $I_{>12}$ & -0.288 & $(0.154)$ \\
\hline Log Likelihood & -14510 & & & -14503 & \\
\hline number of obs. & 32031 & & & 32031 & \\
\hline
\end{tabular}

Note: Estimation results form the multivariate mixed proportional hazard model with unobserved heterogeneity and correlation between the heterogeneity terms. $I_{0-1}, I_{2-4}, \ldots$ are dummy variables for program entry between 0 to 2 months, 2 to 4 months, etc. The model for a constant program effect results in a parameter estimate for $\delta$ equal to $0.362(0.027)$.

According to the quadratic model we find a hump shaped dependence of the

\footnotetext{
${ }^{3}$ Full estimation results and model description are available on request.
} 
program effect on entry time. The effect is maximal for program entry after five months of unemployment. However, during the first year of unemployment the curve is rather flat as can be seen also from Figure 1. The piecewise constant model, which allows for a more flexible function, confirms these results. Here we find a positive program effect, which is almost constant during the first year. ${ }^{4}$ For a later entry the program effect drops to a level insignificantly different from zero.

Figure 1:

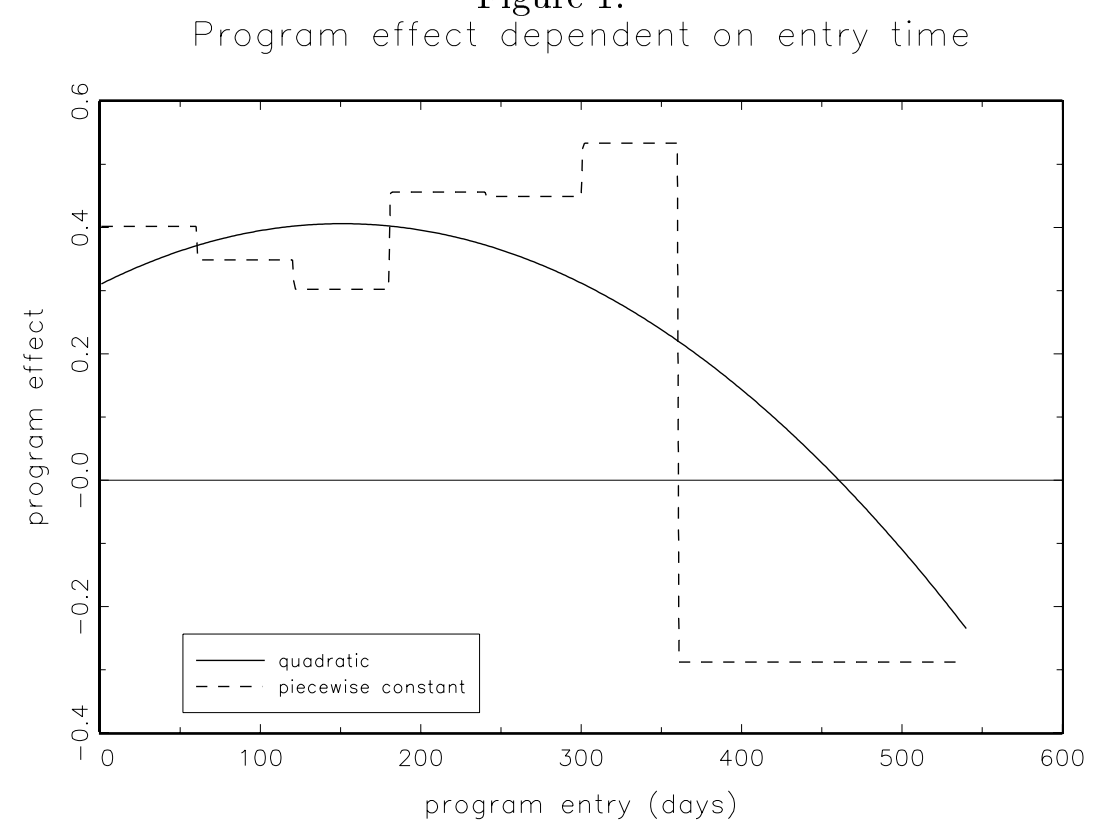

To be able to interprete the size of the program effect we calculate residual unemployment durations for different times of program entry and compare jobcoaching participants with non-participants. The resulting figures from the quadratic model are given in Table $2 .{ }^{5}$ An individual with mean characteristics who has been unemployed for 2 months is expected to stay unemployed for further 111 days, if she does not participate in any program. If she participates in job-coaching, however, the residual unemployment duration is reduced to 77 days. On average residual unemployment durations are reduced by one third if program entry occurs during the first half year of unemployment. The residual unemployment duration is reduced by about $20 \%$ if the participant enters during the second half of the first year of unemployment.

\footnotetext{
${ }^{4} \mathrm{~A}$ Wald test for equality of parameters during the first 12 months does not allow to reject the null hypothesis. The value of the test statistic is $\chi^{2}(5)=5.5$, critical value is 11.07 .

${ }^{5}$ Given the similar values of the log likelihood function in Table 1 we cannot give preference to any of the two models.
} 
Table 2: Residual unemployment durations in days

\begin{tabular}{cccc} 
program entry at day & \multicolumn{3}{c}{ residual duration } \\
& no participation & job-coaching & reduction \\
\hline 60 & 111 & 77 & $31 \%$ \\
120 & 112 & 75 & $33 \%$ \\
180 & 113 & 76 & $33 \%$ \\
240 & 114 & 79 & $31 \%$ \\
300 & 116 & 85 & $27 \%$ \\
360 & 119 & 95 & $20 \%$ \\
420 & 119 & 108 & $10 \%$ \\
480 & 119 & 125 & $-5 \%$
\end{tabular}

Note: residual durations for program participants are calculated on basis of the quadratic model

\section{Conclusion}

We have found a positive program effect of job-coaching that does not vary significantly for program entries during the first year of unemployment. But the effect drops drastically for later entry. Residual unemployment durations are reduced by $20-30 \%$ for program entry during the first year. There is no particular rush to send unemployed to job-coaching programs during the first four months, as the Austrian targeting policy advises, at least when individual transitions from unemployment to employment are concerned. Long term unemployed seem to have specific problems which cannot be addressed by a job-coaching program. They ought to receive special treatment.

\section{References}

Abbring, J. H., van den Berg, G. J., 2003. The non-parametric identification of treatment effects in duration analysis. Econometrica 71, 1491-1517.

Bolvig, I., Jensen, P., Rosholm, M., 2003. The employment effects of active social policy in Denmark. IZA Discussion Paper Series (736).

European Commission, 1998. Employment policies in the EU and in the Member States. Joint Report 1998 .

Lancaster, T., 1990. The econometric analysis of transition data. Cambridge University Press, Cambridge, UK. 
OECD, 1994. The OECD Jobs Study, Paris OECD.

OECD, 1998. Early identification of jobseekers at risk of long term unemployment: the role of profiling, Paris OECD.

Schernhammer, B., Adam, U., 2002. Evaluierung von Jobcoaching 2000. AMS Report (31).

van den Berg, G., 2001. Duration models: specification, identification, and multiple durations. In: Heckman, J., Leamer, E. (Eds.), Handbook of Econometrics. Vol. 5. North Holland, Amsterdam.

Weber, A., Hofer, H., 2003. Active job-search a promising tool? A microeconometric evaluation for Austria. IHS Economic Series Workingpaper (131). 